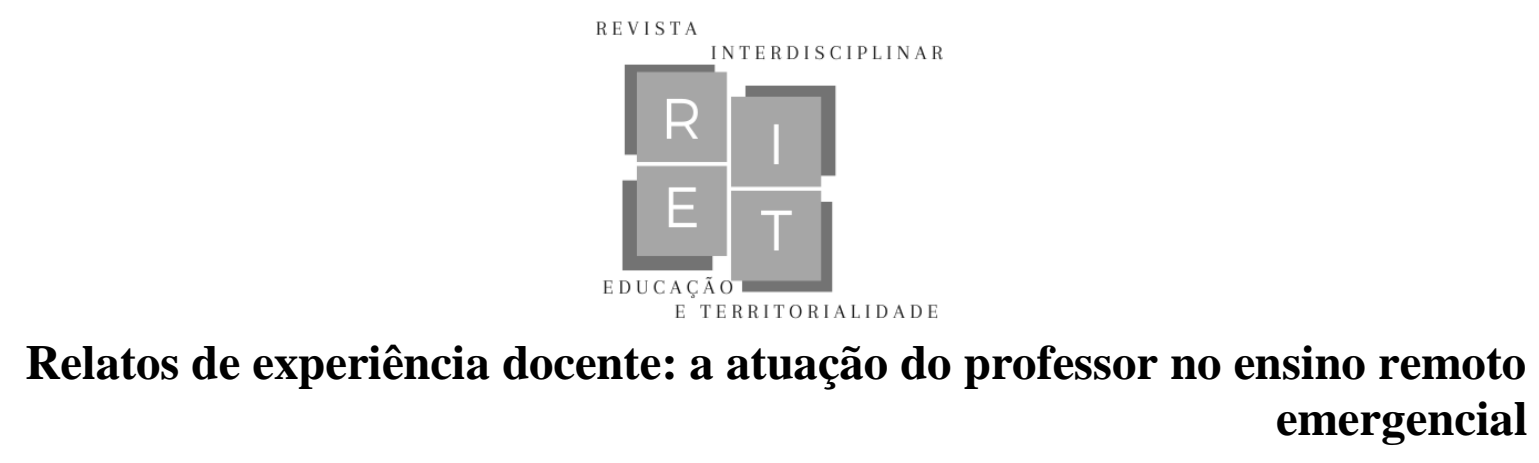

Reports on teaching experience: the teacher's role in the emergency remote teaching

Informes de la experiencia docente: el papel del profesor en la educación remota de emergencia

Fátima Machado

Programa de Pós-Graduação em Letras, Universidade Estadual do Rio de Janeiro (UERJ)

Rio de Janeiro, Rio de Janeiro, Brasil

E-mail: fatimamachado.rj@gmail.com

ORCID: https://orcid.org/0000-0002-7974-2781

Marcelo Martins

Programa de Pós-Graduação em Letras, Universidade Estadual do Rio de Janeiro (UERJ)

Rio de Janeiro, Rio de Janeiro, Brasil

E-mail: marcelo.martins1@terra.com.br

ORCID: https://orcid.org/0000-0001-5016-064

Viviane Caldas

Programa de Pós-Graduação em Letras, Universidade Estadual do Rio de Janeiro (UERJ)

Rio de Janeiro, Rio de Janeiro, Brasil

E-mail: teachervivicaldas@gmail.com

ORCID: https://orcid.org/0000-0003-0180-7079

Resumo: A propagação mundial da Covid-19 e suas consequências ditaram um novo cenário para a educação. A necessidade de isolamento e distanciamento social fez com que as aulas presenciais fossem interrompidas e, então, o espaço escolar passou a existir mediado pelas novas tecnologias e meios digitais. Através de relatos de experiência de professores de instituições públicas e privadas da cidade do Rio de Janeiro, este trabalho pretende postular como esses docentes estão se adequando ao uso da tecnologia e das ferramentas digitais para trabalhar no Ensino Remoto Emergencial, assim denominado. Por meio de uma abordagem qualitativa que engloba breves narrativas e opiniões coletadas em uma rede social, podemos mergulhar no momento presente e tecer reflexões para o futuro cenário da Educação. Os relatos resultam na importância de se despertar para a reflexão acerca da ascensão da cibercultura na sociedade atual e seus impactos na educação e para o papel do professor.

Palavras-chave: Professor. Covid-19. Ensino Remoto Emergencial.

Abstract: The worldwide spread of the Covid-19 resulted in a new scenario for education. The need for isolation and social distancing interrupted face-to-face classes and, then, the school space has been made possible through new technologies and digital media. The narratives from teachers who work at public and private institutions in Rio de Janeiro show us how they have adapted to the use of technology and digital tools to work with the so-

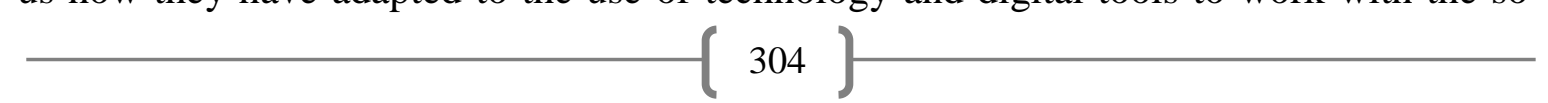

RIET-ISSN 2676-0355, Dourados, v. 2, n. 2, p. 304 a 312, jan./jun., 2021. 
called Emergency Remote Education. With these brief reports on their experience, which teachers posted on a social network, we can dive into the present moment and reflect upon the future of Education, considering the growing rise of cyberculture in today's society and its impacts on education as a way to debate the role of the teacher. Through a qualitative approach that encompasses brief narratives and opinions collected in a social network, we can dive into the present moment and weave reflections for the future scenario of Education. The reports result in the importance of awakening to reflect on the rise of cyberculture in today's society and its impacts on education and for the teacher.

Keywords: Teacher. Covid-19. Emergency Remote Teaching.

Resumen: La difusión mundial del Covid-19 resultó en un nuevo escenario para la educación. La necesidad de aislamiento y distanciamiento social interrumpió las clases presenciales y, luego, el espacio escolar se ha hecho posible a través de las nuevas tecnologías y los medios digitales. Las narrativas de los docentes de instituciones públicas y privadas en Río de Janeiro nos muestran cómo se han adaptado al uso de la tecnología y herramientas digitales para trabajar con la llamada Educación Remota de Emergencia. Con estos breves reportajes sobre su experiencia, que los docentes publicaron en una red social, podemos sumergirnos en el momento presente y reflexionar sobre el futuro de la Educación, considerando el creciente auge de la cibercultura en la sociedad actual y sus impactos en la educación como una forma de debatir el papel del profesor. Con enfoque cualitativo que engloba breves narrativas y opiniones recogidas en una red social, podemos sumergirnos en el momento presente y reflexionar sobre el escenario futuro de la Educación. Los informes dan como resultado la importancia de despertar para el pensamiento sobre el auge de la cibercultura en la sociedad actual y sus impactos en la educación y para el docente.

Palabras Clave: Profesor. COVID-19. Educación remota de emergencia.

Data de recebimento: 01/02/2021

Data de aprovação: 10/06/2021

DOI: $10.30612 /$ riet.v\%vi\%i.13643

\section{Introdução}

No início de março de 2020, surge no mundo uma emergência que coloca o cenário educacional brasileiro em cheque. A Organização Mundial da Saúde (OMS) declara oficialmente que há uma pandemia causada pela mutação do vírus Sars-Cov-2, denominado Coronavírus ou Covid-19. A necessidade de isolamento social para a contenção do espalhamento do vírus afeta todos os setores e segmentos sociais, incluindo as escolas, que interrompem suas atividades também em março do mesmo ano. Vale ressaltar que algumas instituições sequer haviam começado o ano letivo.

O uso da tecnologia e do ensino remoto se tornam uma alternativa ou mesmo a única opção viável para que a escola não seja subtraída em definitivo da rotina dos alunos. Concomitante a esse cenário, os professores precisam se adaptar a uma nova modalidade e, segundo BEHAR (2020), “trocar o 'botão' para mudar de sintonia e começar a ensinar e aprender de outras formas." 


\title{
Relatos de experiência docente: a atuação do professor no ensino remoto emergencial
}

Para situar-se no contexto atual, faz-se útil um breve esclarecimento sobre os conceitos de Ensino Emergencial Remoto, que pode ser confundido com Ensino a Distância (EAD) ou com o conceito de Educação Online. Entende-se como Educação a Distância ou EAD um modelo estruturado com um planejamento didático-pedagógico e estruturas que contemplam "uma arquitetura pedagógica composta pelos aspectos organizacionais, de conteúdo, metodológicos, tecnológicos e as estratégias pedagógicas a serem empregadas" (BEHAR, 2020).

Sobre a Educação Online, Santos (2019, p. 61-62) afirma que "não é uma mera evolução das práticas massivas de EAD" e sim um fenômeno inerente à cibercultura. A autora expressa bem a distinção na citação a seguir:

\begin{abstract}
O que caracteriza a educação a distância é principalmente a separação física entre os sujeitos aprendentes e/ou formadores e seus dispositivos e narrativas de formação, a exemplo dos conteúdos, tecnologias, objetos de aprendizagem e o próprio universo cultural e comunicacional dos sujeitos. Já no caso da educação online os sujeitos podem até encontrar-se geograficamente dispersos, entretanto, em potência estão juntos e próximos, compartilhando informações, conhecimentos, seus dispositivos e narrativas de formação a partir da mediação tecnológica das e com as interfaces e dispositivos de comunicação síncronas e assíncronas e de conteúdos hipertextuais disponíveis no ciberespaço a partir do AVA.
\end{abstract}

Já o ensino remoto emergencial tem caráter temporário e emergencial devido ao fato de que em aproximadamente três meses os professores tiveram de se adaptar a uma transformação que certamente precisaria de mais tempo para chegar a melhores práticas (BEHAR, 2020). Como características fundamentais, o Ensino Remoto Emergencial se desenvolve em tempo síncrono, por intermédio de videoaulas e de conferências web. As atividades vão adiante em um Ambiente Virtual de Aprendizagem (AVA) de maneira assíncrona.

A fim de saber mais sobre o ensino remoto emergencial, levantamos a seguinte questão em uma postagem no Facebook: "Como tem sido a atuação e a adaptação dos professores ao ensino remoto emergencial?". As respostas-relatos foram compartilhadas por professores de escolas públicas e particulares do Rio de Janeiro na rede social e nos servem como ponto de partida para subsidiar o pensamento e o debate sobre os caminhos traçados ao longo do período pandêmico. As narrativas abordam aspectos diversos do ensino remoto e considerá-las é uma forma de valorizar a função do contexto e o papel dos sujeitos na construção de sentidos.

RIET- ISSN 2676-0355, Dourados, v. 2, n. 2, p. 304 a 312, jan./jun., 2021 


\section{Relatos de experiência docente: a atuação do professor no ensino remoto emergencial}

A voz dos professores através de suas experiências circunscritas espaço-tempo desvela tensões, ressignificações, dúvidas, caminhos, tendências e possibilidades que possibilitam tecer análises e impulsionar reflexões sobre os novos formatos e meios encontrados para as aulas escolares durante o período da pandemia em que, também, emerge a discussão sobre a preparação e o papel dos professores que atuam em contextos digitais e remotos na era da cibercultura. Esses questionamentos nos permitem (re)pensar questões acerca da educação além dos muros físicos do espaço escolar, assim como considerar sobre os legados e impactos deste momento singular para os passos futuros na Educação do Brasil e do mundo.

\section{A voz docente: relatos sobre o ensino remoto emergencial}

A situação-limite imposta pelo contexto pandêmico para a educação que demandou uma ressignificação da sala de aula, não só de suas práticas, mas de como ela se apresenta no espaço-tempo e como os sujeitos (docentes e alunos), mediam e participam das interações e constroem possibilidades de construção de conhecimento. De acordo com Liberali (2020), a ação docente neste cenário:

...prescinde de criar bases para ir além de nós mesmos e de nossas limitações, sem jamais desprezar as forças que atuam na contramão de nosso fazer: sem ingenuidade de pensar que temos o poder ilimitado de dar conta de todo o caos que vivemos, mas com a energia criativa para pensar em formas e arranjos que nos levem além do que já foi experimentado.

Para melhor compreender os desdobramentos de um primeiro momento inserido nessa realidade, resgatamos o caráter dialógico da produção de conhecimento e trazemos à tona reflexões sobre a sala de aula a partir do discurso dos professores. Esses discursos precisam se fazer evidentes e são pontos chaves para analisar os legados e consequências deste momento singular.

Ao observar relatos de docentes do Ensino Fundamental II das redes públicas e privadas da cidade do Rio de Janeiro em interação com a postagem publicada na rede social Facebook, é possível evidenciar alguns posicionamentos em comum. Entre eles, podemos citar: a falta de familiaridade para o uso de ferramentas digitais; a ausência de formação ou tempo curto de treinamento para trabalhar nesse contexto; e as demandas exigidas pelo ensino remoto emergencial, como gravar vídeos, planejar atividades e adaptar conteúdo, muitas vezes personalizados para atender as especificidades de cada turma. A preocupação

RIET- ISSN 2676-0355, Dourados, v. 2, n. 2, p. 304 a 312, jan./jun., 2021 


\section{Relatos de experiência docente: a atuação do professor no ensino remoto emergencial}

dos professores com o acesso dos alunos menos favorecidos às plataformas digitais também foi bastante citada nas postagens.

\section{Na "marra"}

Em relação às propostas de trabalho ou soluções apresentadas pelas escolas, sejam estas públicas ou privadas, a fim de atender ao ensino remoto emergencial, os professores apresentaram diferentes relatos, porém descrevem opiniões similares. É possível notar que as narrativas sobre essa questão, no geral, girem em torno da ausência de treinamento ou direcionamento das instituições, mas também perpassam a formação base do docente (P1, $\mathrm{P} 2)$, a adaptação de professores mais velhos às novas tecnologias ( $\mathrm{P} 4)$, a crítica às políticas educacionais e ao sistema de ensino como um todo (P9 e P10).

P1: Muita informação em pouco espaço de tempo e a preparação é na marra mesmo. (...) precisamos de (...) uma formação decente para todos os profissionais da educação.

P2: (...) não estávamos preparados para trabalhar nesse ambiente. Não tivemos esse tipo de instrução em nossa formação.

P3: (...) não me sinto preparada, não tenho habilidade para este tipo de trabalho. Não me sinto confiança na modalidade

P4: (...) alguns professores, mais antigos, tiveram que se atualizar e aprender "na marra" a usar ferramentas nunca usadas antes.

P5: Trabalhei na rede particular (...) e não me sentia preparado.

P6: Não me sinto confortável, pois não houve preparo tanto para os alunos quanto para os professores.

P7: Não houve treinamento, suporte, muito menos material e equipamento para desenvolver as atividades...

P8: Vieram aulas on-line. Não, não estava preparada! Depois de anos dominando minha sala de aula, tive que aprender a dominar App, plataformas, montar avaliações, PPT... tudo informatizado! Loucura!

P9: Contamos também com as forças políticas para que proporcionem a esses profissionais o treinamento necessário.

P10: Não se trata de um desafio é uma emboscada onde nos tornamos vítimas de um sistema, que pretender nos usar, para ocultar o seu total despreparo...

Mediante o exposto, é importante salientar as competências necessárias na formação de futuros professores considerando a era da cibercultura: o fomento de um docente reflexivo que articule inovação, olhar crítico e teoria (TARDIF, 2014).

\section{Novos papéis (ou muitos papéis)?}




\section{Relatos de experiência docente: a atuação do professor no ensino remoto emergencial}

Outro apontamento relevante e que merece destaque se relaciona ao redimensionamento do papel professor. Não obstante, reinventar, ressignificar e reconsiderar foram verbos recorrentes nos comentários feitos pelos professores.

P11: Tive que me reinventar, ressignificar meu trabalho (...)

P16: Tivemos (a equipe e eu) que reconsiderar a atuação e fazer um jogo "interativo" (...) Todas as aulas preparadas, com conteúdos e estratégias diferenciadas...

P12: Tenho buscado outra forma de passar o conteúdo, de uma forma mais lúdica, com vídeos, música, quadrinhos e etc.

P17: Alunos compartilham a tela deles com a turma e apresentam algum tema.

Embora as questões aqui levantadas necessitem de uma análise mais detalhada e aprofundada, elas demonstram brevemente uma direção importante para o professor, seus papéis e sua formação. Segundo Duran (2020):

Da educação formal à aprendizagem ubíqua (onipresente, distribuída por toda parte, on demand), os professores deixaram de ser os únicos detentores da informação e, por esse motivo, seu papel está sendo ressignificado e reinventado. De transmissores da informação passaram a ser mediadores, coautores e curadores do conhecimento. Ainda que a transmissão faça parte do trabalho docente, na era digital os profissionais da educação são impelidos a se conectarem à inteligência coletiva, juntamente com seus alunos, nas redes sociais e comunidades virtuais de aprendizagem. (grifo nosso)

Num contexto social cada vez mais multissemiótico e interconectado, com diversas formas de se acessar conhecimento e informação, espera-se que o docente esteja preparado para guiar os alunos a um engajamento na construção de conhecimento, bem como usar e promover oportunidades de uso das novas mídias, percorrer e oferecer percursos de aprendizado variados e, não menos importante, colaborar com outros professores compartilhando ideias, atividades e planejamentos (KALANTZIS et al, 2016).

\section{Diferenças sociais reforçadas}

Soares e Santos (2012, p. 309) apontam que:

A integração ao mundo tecnológico, midiático e informacional impõe-se como uma exigência quase universal, embora venha se realizando de forma desigual, e até mesmo marginal, conforme as diferenças sociais, econômicas, políticas e culturais entre as regiões do planeta e do país, entre os grupos sociais e entre os indivíduos.

RIET- ISSN 2676-0355, Dourados, v. 2, n. 2, p. 304 a 312, jan./jun., 2021 


\section{Relatos de experiência docente: a atuação do professor no ensino remoto emergencial}

Além disso, segundo Liberali (2020, p.14), há uma preocupação com os descaminhos que a educação arrisca trilhar ao refletir o que a autora chama de necroeducação:

Enquanto alguns alunos da rede privada passaram a ter acesso a toda forma de atividades, por múltiplas plataformas e aplicativos remotos, com professores trabalhando à exaustão para contribuir com um padrão de qualidade e expectativas altíssimos em pouco espaço de tempo, alunos de redes públicas, locais remotos ou mesmo contextos mais empobrecidos foram deixados a viver a morte-em-vida. (...) Para muitos alunos das comunidades mais pobres, (...) com acesso restrito ou nulo à internet, poucos conseguem realizar as propostas feitas pelos governos para suprir a ausência de aulas presenciais.

Os relatos a seguir são de professores da rede pública estadual e municipal do Rio de Janeiro.

P12: Eu me sinto limitada tendo que elaborar atividades onde nem todos tem um bom acesso à internet ou um celular (tenho alunos de $1^{\circ}$ ano ao $3^{\circ}$ ano).

P13: Embora haja a proposta de diversas atividades, através de vídeos e exercícios postados dentro de uma plataforma e enviados pelo wpp, nem todos os alunos possuem acesso. O retorno é muito baixo.

P14: As ferramentas são excelentes, porém muitos não têm acesso à internet.

P15: Os alunos reclamam muito. Dizem que não tem internet em casa, não fazem as atividades, não se interessam.

P3: O ensino a distância requer autonomia de estudo e estrutura para que flua positivamente, por parte da família do aluno e as limitações são imensas, principalmente para o professor e o aluno da rede pública.

P9: O grande desafio é contar com as forças políticas para que garantam o acesso à toda tecnologia aos alunos, bem como o pacote de dados necessário.

Observamos que os depoimentos dos professores corroboram com as concepções dos autores citados acima e evidenciam a preocupação dos professores com a democratização do acesso a equipamentos e conexão por parte dos alunos, não só para garantir a eficácia e o alcance de suas aulas, mas principalmente para que a educação não seja reprodutora de uma lógica excludente e segregadora.

\section{O lado bom das coisas}

Além do tom de lamento, que por vezes soa quase que como um pedido de socorro, alguns depoimentos também versam sobre pontos positivos e aspectos que podem se tornar um legado significativo no período pós-pandemia, como novas práticas de ensino, estratégias

RIET- ISSN 2676-0355, Dourados, v. 2, n. 2, p. 304 a 312, jan./jun., 2021 


\section{Relatos de experiência docente: a atuação do professor no ensino remoto emergencial}

e abordagens que integrem os caminhos disponíveis e possíveis para as relações de ensinoaprendizagem.

P14: As ferramentas são excelentes...

P4: (...) temos vistos talentos sendo descobertos neste tempo, oportunidades de novos estudos, principalmente os tecnológicos.

P7: Transforma toda a parte pedagógica, mas é um incentivo ao novo. (...) Foi um estímulo a novos horizontes, novas formas de aprendizagem.

P10: O maior benefício foi o reconhecimento da necessidade urgente de aprimoramento.

P9: (...) vejo o ensino remoto como uma possibilidade real de ensino complementar na educação em geral. $\mathrm{O}$ ambiente virtual é uma realidade em todas as esferas e na educação não será diferente...

P18: Sempre gostei de tecnologia e nesse momento ela tem sido grande aliada. Uso nas aulas algumas ferramentas tecnológicas que nos ajudam a sair da rotina. Os desafios são muitos (...) mas com criatividade e inovação podemos alcançar bons resultados.

Diante da necessidade de isolamento e consequente interrupção total das aulas presenciais, houve uma demanda de soluções e respostas imediatas para um contexto sem antecedentes na prática pedagógica. Enxergar os pontos positivos, encontrar caminhos factíveis e repensar soluções para trabalhar com os possíveis ecoam na fala dos professores acima, mostrando que situações emergenciais podem impulsionar para "a construção do inédito viável" (LIBERALI, 2020).

\section{Algumas considerações}

A verdade é que ninguém considerava prever os caminhos da educação que se desenharam por conta do cenário da pandemia. Educadores, pesquisadores e instituições não poderiam supor que o uso da tecnologia e dos meios digitais assumiriam o papel principal de uma hora para outra, ainda que fossem amplamente usados como complementares no processo ensino-aprendizagem. Igualmente, alunos, pais, responsáveis e a comunidade escolar como um todo também parecem ter recebido essa questão com surpresa, o que é compreensível sob certos aspectos, especificamente sobre perspectivas mais tradicionais social e historicamente construídas sobre a relação professor-aluno e sobre a forma como se aprende e como se ensina.

Os professores estavam adaptados à realidade da sala de aula presencial. Suas práticas giravam em torno do encontro. Uma parte considerável desses professores jamais havia recebido, pelo menos, algum tipo de capacitação ou instrução para esta nova demanda.

RIET- ISSN 2676-0355, Dourados, v. 2, n. 2, p. 304 a 312, jan./jun., 2021 


\section{Relatos de experiência docente: a atuação do professor no ensino remoto emergencial}

Tratou-se, portanto, em alguns casos, da adaptação daquilo que já se sabia fazer na sala de aula presencial para o ambiente virtual. Em outros, da potencialização do uso das ferramentas digitais para práticas centradas no aluno como figura ativa na construção do conhecimento. Em meio a isso, há a busca por superar as desigualdades de acesso e recursos, tanto por parte do corpo docente quanto dos alunos.

Resta, portanto, valer-se deste momento para refletir e (re)pensar no papel da educação no cenário atual, na atuação dos professores e nas relações de ensino-aprendizagem que se construirão a partir desse contexto. Com isso, cabe também avaliar como melhorar o preparo dos professores pautado em uma formação que acompanhe a realidade tecnológica que vivemos. E, acima de tudo, usar a educação, seja em qual for a modalidade, como forma de resistir às forças hegemônicas e de buscar um mundo mais justo e igualitário. De que formas? São muitas as possíveis respostas e, de certo, sendo uma questão recente, ainda há muito a investigar, avaliar e debater. Que este seja um convite para reflexões e que incite novas pesquisas e discussões.

\section{Referências}

BEHAR, P. O Ensino remoto emergencial e a educação a distância. Jornal da Universidade, Rio Grande do Sul, 2 jul. 2020. Disponível em: https://www.ufrgs.br/jornal/o-ensino-remotoemergencial-e-a-educacao-a-distancia/. Acesso em: 20 out. 2020.

DURAN, D. Coronavírus viraliza educação on-line. Jornal da USP, 18 mar 2020. Disponível em: https://jornal.usp.br/artigos/coronavirus-viraliza-educacao-online/ . Acesso em: 20 jul 2020.

KALANTZIS, M; COPE, B.; CHAN, E.; DALLEY-TRIM, L. Literacies. Cambridge: Cambridge University Press, 2012

LIBERALI, F. Construir o inédito viável em meio à crise do Coronavirus - Lições que aprendemos, vivemos e propomos. In: LIBERALI, F.; FUGA, V.; DIEGUES, U.;

SANTOS, E. Pesquisa-Formação na cibercultura. Teresina: EDUFPI, 2019.

SOARES, C. SANTOS, E. Artefatos tecnoculturais nos processos pedagógicos: usos e implicações para os currículos. In: ALVES, Nilda. Libâneo, José Carlos. Temas de Pedagogia: diálogos entre didática e currículo. São Paulo: Editora Cortez, 2012. (p. 308- 330).

TARDIF, M. Saberes docentes e formação profissional. 17 ed. Petrópolis, RJ: Vozes, 2014. 